\title{
Emergency shelter topologies: locating humanitarian space in mobile and material practice
}

\author{
Aurora Fredriksen \\ Leverhulme Centre for the Study of Value \\ School of Environment and Development \\ The University of Manchester \\ Arthur Lewis Building, Oxford Road, Manchester, M13 9PL, U.K. \\ Email: aurora.fredriksen@manchester.ac.uk
}

\begin{abstract}
Focusing on two different devices commonly deployed in emergency shelter responses, the emergency family tent and the shelter kit, this article traces the topological associations of humanitarian spaces as enacted through humanitarian practice. The emergency family tent is shown to effect humanitarian space within the associations of a network topology by acting as an 'immutable mobile', connecting different places of humanitarian crises with each other through stabilising relationships between them across space and over time and ordering space according to a sequential timeline of action. Alternately, the shelter kit is shown to effect humanitarian space within the associations of a fluid topology by acting as a 'mutable mobile', connecting the sites of crisis not through stabilisation but through adapting to a wide variety of local contexts and conditions and ordering space according to an overlapping and partly simultaneous timeline of action. These different 'shelter topologies' are shown to convey different assumptions about, and underlie different topographic renderings of, humanitarian space.
\end{abstract}

Keywords: humanitarian space, topology, im/mutable mobility, devices, emergency shelter Word count 9,995 


\section{Introduction: Locating humanitarian spaces in emergency shelter responses}

Since gaining broad usage among policy and practitioner circles in the 1990s, the phrase 'humanitarian space' has been the subject of increasing contestation and confusion (Hubert and Brassard-Boudreau, 2010; Collinson and Elhawary 2011; Tennant et al 2010). A large part of this lack of agreement over what humanitarian space is, or should be, stems from the larger discord over the appropriate meaning and scope of the term 'humanitarian' (see for example, the opposing views of Rieff, e.g. 2002 and Ignatieff, e.g 1997). Seeing the practical impossibility of reconciling conflicting claims on the designation 'humanitarian', some observers have suggested abandoning use of the phrase 'humanitarian space' altogether to avoid operational confusion (e.g. Hubert and BrassardBoudreau, 2010). Others have conversely advocated for adopting a definition of humanitarian space broad enough to encompass all concurrent claims on the designation ‘humanitarian' (e.g. Collinson and Elhawary 2011). While offering the allure of a 'solution', in their fixation with resolving the multiple and competing understandings of 'humanitarian', each of these tacks ends up sidelining the 'space' in 'humanitarian space' and so are both, ultimately, unsatisfying. After all, notions of space and spatiality are central to the many different iterations of humanitarian space, for example in the humanitarian demand for an operational space in which humanitarian actors may offer assistance without interference, the claim to an ostensibly neutral and impartial 'third' space of exception, hors de combat, protected by International Humanitarian Law, or the occupation of a symbolic space of witness to the suffering of others. Accordingly, getting a grip on the spaces and spatialities of humanitarian action is a crucial challenge in the task of untangling humanitarian space. 
In an effort to respond to this challenge, this article takes the case of emergency shelter provision as a site for examining the mobile and material practices, arrangements, and temporal entanglements through which humanitarian spaces are enacted. More particularly, this article explores the mobilities and materialities of two commonly deployed emergency shelter devices, the emergency family tent and the shelter kit, as a means of empirically tracing humanitarian space as it is enacted in the course of emergency shelter responses. ${ }^{1}$ In thus attending to the ways in which these two shelter devices participate in enacting humanitarian space, this article joins the ever growing body of work concerned with the role objects and technologies play in co-articulating social phenomena. ${ }^{2}$ Such a device-centred approach signals a concern with empirically located analysis (Marres 2012), challenging the assumption that humanitarian space can be satisfactorily understood in reference only to abstracted processes or universal categories. This is not to dismiss the abstract formulations of humanitarian space that are put forward by groups like the International Committee of the Red Cross (ICRC) and Médecins Sans Frontières (MSF, whose former president Rony Brauman is credited with bringing 'espace humanitaire' into broad usage in the 1990s). The discursive force of such formulations is certainly central to many contemporary humanitarian practices, legal and political positionings, and imaginaries. Yet many critiques and contests over the meaning of humanitarian space arise precisely in the apparent disconnect between such abstract, or ideal, formulations and actual, situated humanitarian practices. However, rather than

\footnotetext{
1 The empirical cases presented in this article draw on a series of in-depth interviews with humanitarian officials from relevant UN agencies, Red Cross bodies and humanitarian NGOs, as well as participant observation at Red Cross-led shelter sector trainings and an extensive documentary analysis conducted in the course of a larger project (Fredriksen 2012).

2 As Marres (2012, page 162n) points out, the concept of the device has a "heterogeneous intellectual pedigree"; here the term is deployed in accordance with Marres' usage, that is, in the spirit of actor-network theory (ANT) and 'after-ANT' work, as material objects that participate in the course of action (e.g. Law and Hassard 1999; KnorrCetina 1997; Latour 2005).
} 
joining this chorus by conceptually arranging abstract formulations and actual practices on either side of an ideal/real divide, the challenge here is to locate the former through attention to the latter. That is, the aim is to trace how various abstract formulations of humanitarian space are conveyed and translated through the complicated, imperfect practices and material designs of humanitarian responses (see Redfield 2011, page 53 on this point in relation to the humanitarian practice of neutrality). The focus on the mobilities and materialities of shelter devices, then, turns the analysis away from the definitional question of what humanitarian space is (ideally, actually, or otherwise), toward the empirically sited question of how humanitarian spaces come to be enacted in the material and mobile practices of humanitarian emergency shelter responses.

A focus on shelter devices has the additional advantage of drawing attention to the progressive technicalisation of humanitarian responses (Barnett 2008; Calhoun 2004, 2008; Tsui and Myint-U 2004). While the provision of emergency shelter has long been a central component of humanitarian responses to crises, since the 1990s shelter has been increasingly marked out as a specialised sector of humanitarian response requiring a high level of technical expertise (Davidson and Price, 2011). Limits to what humanitarian shelter responses might hope to accomplish are increasingly viewed as challenges that can be overcome through enhanced technical capacities. Accordingly, items long used in humanitarian shelter responses, including tents and collections of building tools and tarpaulins, have been given renewed attention as engineers and architects join experienced humanitarian actors in (re)designing these go-to emergency shelter items. As co-lead agencies of the global Emergency Shelter Cluster, ${ }^{3}$ UNHCR and the

\footnotetext{
${ }^{3}$ Launched by the Inter-Agency Standing Committee (IASC) in 2005 as part of the UN-led humanitarian reform initiative, the 'cluster approach' is a mechanism for the coordination of humanitarian action by sector (e.g. health, shelter, water and sanitation and so on) at both 'global-' and 'country-level'.
} 
International Federation of Red Cross/Red Crescent Societies (IFRC) are at the forefront of collaborative efforts to enhance the technical capacities of the emergency shelter sector. The development and deployment of the emergency family tent and the shelter kit by these agencies is an outcome of the humanitarian shelter sector's growing focus on finding technical solutions to solve emergency shelter problems.

As in other fields, technical and logistical advances and smarter design are increasingly positioned within the humanitarian profession as keys to solving humanitarian problems, especially in sectors (re)framed as 'technical' like water and sanitation and shelter. By appearing to stand outside of politics, technical solutions convey and reinforce humanitarian identities of neutrality and impartiality. Yet, as a number of researchers have shown, design and technology are both the product of prior cultural and political assumptions and uses (e.g. Haraway 1991; Latham and Sassen 2005; Latour 1991) and are capable of forwarding particular political agendas (e.g. Marres 2012). As such, the associating of design and technology with neutrality in humanitarian practice has been charged with obscuring certain humanitarian (bio)political projects or alignments (e.g. Agamben 1998; Lacy 2008; Weizman 2007). At the level of humanitarian practice, however, the goal of enhancing the technical capacity of humanitarian responses continues to be understood as a politically neutral way of improving humanitarian outcomes and, as such, has remained largely unquestioned (Tsui and Myint-U 2004; cf. Terry 2002). ${ }^{4}$ Therefore, following the design and deployment of particular shelter devices is also a way of uncovering the assumptions (bio/political, professional, otherwise) that are carried within the material design and mobilities of these technical solutions to humanitarian problems.

\footnotetext{
${ }^{4}$ This lack of reflection on the validity of accepted goals recalls Mol's (2002, pages 172-3) discussion of the same in modern medical practice.
} 
Focusing on shelter devices, then, allows for a particular empirical tracing of humanitarian space attendant to the ways in which technological solutions to humanitarian crises can carry certain assumptions in their material form and mode of mobility. In this turn to devices, however, the question of space and its enactment remains central. The following section unpacks the conceptualisation of space in humanitarian space deployed in this paper, situating the analysis in relation to other social scientific work on humanitarian space and introducing the concept of topologies as it is used here to untangle the relationships between mobility, materiality and temporality in humanitarian spatial practice.

\section{Mobility, materiality and temporality in humanitarian spatial practice}

In contrast to spatial forms tied to specific places or territories (for example the space of nation-states), humanitarian space is tied to events - to humanitarian crises and is thus conventionally both highly mobile, moving into the sites of crises as they occur around the globe, and temporally delimited to the aftermath of crisis. This global mobility and limited engagement with the locations of crisis has drawn critique from those concerned with the homogenising tendencies of, and forms of biopower effected by, humanitarian actors to the detriment of populations receiving humanitarian assistance (e.g. Debrix 1998; Fassin 2012; Fassin and Pandolfi 2010). While offering critical insight into the potential biopolitical effects of humanitarian action, many of these critiques suffer from an inadequate conceptualisation of humanitarian space and spatial practice, without which the relational locations of such power effects are not fully visible. Indeed, in many of these works, space is not conceptualised at all. When it does appear in the analysis, space is often presented in a grid-like Cartesian form as a background to action. For example in Pandolfi's (e.g. 2003; 2008) work on the 'mobile sovereignty' of 
humanitarian action, humanitarian space is positioned as a function of humanitarianism's 'emergency temporality' wherein the imperative to act in the urgent present of crisis drives "the occupation of space, the invasion of territory, and the crossing of borders" (Pandolfi, 2003, page 376). While an undoubtedly valuable contribution to the formulation of temporality in relation to humanitarian action, as with many analyses not attuned to questions of space as such, in Pandolfi's formulation humanitarian space is reduced to a static container (Taylor 1994) for humanitarian activity, relegated to the role of "a static backdrop to time's activity" (Thrift 2006: 142). How space itself might interact with temporality, unfold and potentially come to be (re)ordered through the mobile and material practices of humanitarian occupations, invasions and crossings, is left unanswered.

An important exception to this failure to pay serious attention to space in the literature on humanitarian action is Redfield's (e.g. 2008; 2013) work on humanitarian spatial practices, most particularly that on the 'vital mobility' of MSF's biomedical kits. In this work Redfield attends to the specific practices and material arrangements through which humanitarian space is performed and (temporarily) stabilised through the design and circulation of standardised emergency medical kits. In this formulation, MSF's biomedical kits do not simply enter and leave spaces of crisis rendered as static backgrounds to, or containers of, humanitarian action, but rather, they actively participate in stabilising and (re)ordering of spaces as, at least provisionally, bumantiarian spaces. Echoing Akrich (1992) and Latour's (1992) work on scripts, Redfield explains that MSF's kits effect "a mobile, transitional variety of limited intervention, modifying and partially reconstructing a local environment around specific artefacts and a set script" (2008, page 
161). That is, they effect humanitarian spaces by stabilising relationships of disasters as dictated by their standardised material form and enabled by their easy mobility.

As I will elaborate below, emergency family tents exhibit many parallels with Redfield's description of MSF's biomedical kits, effecting a similarly constituted, provisionally stabilised and temporally limited version of humanitarian space. However, where Redfield follows the materiality and mobility of a single device (the biomedical kit) in order to illustrate how a particular organisation (MSF) enacts and stabilises humanitarian space, my use of a comparison between two different shelter devices draws attention to the ways in which different types of materiality and mobility effect different humanitarian spaces. The humanitarian spaces temporarily stabilised through the deployment of MSF's biomedical kits are one way of doing humanitarian space through one mode of spatial associations. But there are other possibilities, other heterogeneous associations of humanitarian space.

To help illuminate the potential variance in humanitarian spatial possibilities, this article employs the concept of topologies. As Rose and Wylie (2006, page 475) concisely explain, topology can be formally defined as "the study of object properties which are maintained even when the object is stretched, compressed, twisted or otherwise altered (but not torn)". In this sense, how objects move and the character of their materiality are central properties for tracing topological forms. To illustrate this more clearly, this article draws on the topological metaphors put forward by Mol and Law (1994; Law and Mol 2001; 2010; see also de Laet and Mol, 2000), conceiving of the humanitarian space ordered through the movements and materiality of the emergency family tent as reflecting a 'network topology' and that of the shelter kit as reflecting a 'fluid topology'. While the former is characterised by the stabilisation of associations and exclusion of 
difference so as to effect invariance, in the latter associations between places, people and things are not fixed, but instead positions and meanings may be open and overlapping (Law and Mol 2001).

In addition to the implication of material and mobile practices in the topological analysis of spatial forms, I suggest that temporality can also be fruitfully engaged through topological analysis. Accepting the conceptualisation that spaces/spatialities are always already entangled with times/temporalities (e.g. Massey 2005; Deleuze 1988), the topological analysis of humanitarian spaces herein is necessarily also concerned with humanitarian temporalities. Returning to Pandolfi's work on the 'emergency temporality' of humanitarian action, topological analysis can help move the analysis toward a conceptualisation of how this temporality of emergency not only urgently drives action over or across space, but is co-articulated with humanitarian spatial practices in the enacting of humanitarian space-times.

Finally, in addition to signalling attention to the relational properties of different kinds of spaces and allowing a more nuanced examination of the articulation of humanitarian spatial practice with humanitarian temporal practice, the use of topology here also references an older usage of the concept, as put forward in the early $20^{\text {th }}$ century by the head of the French Service Géographique de l'Armeé, Géneral Berhaut: The principal object of topology... is to furnish the topographer with the analytic elements of the forms of the relief, for the more thoroughly these forms are understood by the topographer the more successful will he be in their delineation (Berthaut 1912, as translated in Matthes, 1912, page 336).

In enthusiastic support of Berthaut's formulation, American geographer François Matthes adds that the lack of topological knowledge on the part of an "uninformed" 
topographer "speaks from every line he draws; it betrays itself in the meaningless, wooden forms that characterize his sketches" (Matthes 1912, page 336-7). In other words, understanding the topological forms underlying humanitarian spaces can inform the various ways in which the material, discursive and imaginary lines and contours of these spaces are drawn. Whether one's intention is to critique, defend or simply make sense of humanitarian spaces, understanding the topological associations shaping that space are critical if we are to avoid drawing 'meaningless, wooden' topographies.

With this multivalent conceptualisation of topological space is mind, the remainder of this article traces the topologies of humanitarian space and the topographies they render in the case of emergency shelter responses, exploring the mobilities, materialities, and temporalities of, first, the emergency family tent and, second, the shelter kit.

\section{Humanitarian space as network topology}

While the tent has long been a mainstay of modern humanitarian relief efforts, its design has changed dramatically over the years. Reflecting on this point in 2010, just after the launch of the new emergency family tent, the then UNHCR Global Shelter Cluster Coordinator told me

The tent has been in use since one can remember ... But it's, it's changing so rapidly... We remember having tents fifteen, twenty years ago which were carried by five people to load on a truck with bamboo poles which were three metres long and then you have to-because you cannot transport it by air — so [you have to] just send the tarpaulin out and there's nothing to support it. People would chop trees, you have environmental damage and all the rest.

Experiences such as those recounted here, where tents have been unable to work as emergency shelters due to logistical obstacles, or where they have worked as emergency shelters but at the expense of environmental degradation or some other unintended and 
undesirable outcome, were once accepted as unfortunate, but largely unavoidable, stumbling blocks in the delivery of humanitarian assistance in the context of a humanitarian emergency.

In more recent years, however, these experiences have been reformulated as 'lessons learned' and used as examples of challenges that can be overcome through investing in research and design for more technically advanced emergency tents supported by a more advanced humanitarian logistical infrastructure. ${ }^{5}$ Marking the most ambitious emergency tent redesign of recent years, in 2008 UNHCR, IFRC, in their capacity as leaders in the humanitarian shelter cluster, along with the International Committee of the Red Cross, ${ }^{6}$ embarked on two years of inter-organisational research and design aimed at building a better tent. Describing this exhaustive research process, the UNHCR Global Shelter Cluster Coordinator noted that the new design addresses issues like fire retardence, because we have had camps which burned down in a sort of very quick way and having loss of lives as well. So there's research on what type of retardant goes into [new tent specifications]; there's research on the fabric, whether it's raining so it doesn't seep through, that it's the right type of material, that it's not cotton that becomes too damp when it is raining, that it's not only plastic which becomes too hot or melts when it's too hot; to the total weight of the tent, that should not be more the 50 kilograms [so it] can be put on the planes and helicopters that can go in, so the packaging should be small; that we do not have timber to support the tent that it's to be different poles, but those poles should be strong enough to withstand the wind and the dust and snow.

\footnotetext{
${ }^{5}$ Along with architects and engineers, logistics experts have also been enrolled in the task of advancing the technical capacities of humanitarian shelter responses. Although there is not the space here to expand on the role of logistics in enabling global mobilities, see, for example, Cowen 2010.

${ }^{6}$ Due to its strict commitment to practicing neutrality and independence, the ICRC is not an official member of the Shelter Cluster. However, as one of the largest providers of emergency shelter relief in humanitarian responses, ICRC acts as an important 'observer' member of the shelter cluster, participating in cluster meetings and collaborating with other shelter organisations.
} 
As this description indicates, the joint UNHCR/IFRC/ICRC research for the new family tent drew together the extensive field experiences of each of these agencies, ultimately producing a set of joint specifications that embody a variety of lessons learnt in past responses and carrying these forward to improve responses in the present. By bringing together the different accumulated experiences and expertise from the three agencies, this inter-organisational research process made discrepancies between experiential knowledge about tents visible (see Eisenstein, 1979; Latour, 1986), allowing for a reassessment of individual specifications and a joint redesign that is more technically advanced than any previous family tents.

In drawing together the experiences and expertise of UNHCR, IFRC and ICRC into one collective set of specifications, the emergency family tent embodies decades of organisational 'lessons learned' from specific crisis responses in its material form. That is to say, the emergency family tent connects different humanitarian crises and responses to one another over time and across space by carrying lessons learned in one humanitarian response forward in its material form to stabilise other humanitarian crises as they unfold. Past organisational experience of a fast-burning fire in a refugee camp years ago, for example, is carried, in the material form of the new family tent's fire retardence, to stabilise life in refugee camps recently erected in Pakistan, Ethiopia and Libya. Similarly, organisational experience of tents being too heavy to transport by air 15 years ago recollected above by the UNHCR Global Shelter Cluster Coordinator - was carried, in the material form of the new family tent's compact, lightweight design, forward into the 2011 mass airlift of family tents to the Dabaab refugee camp in Kenya to stabilise the Somali refugee crisis there. In connecting and stabilising different sites of humanitarian crisis across space and over time in this way, the emergency family tent moves as an 
'immutable mobile', that is, as an object which "succeeds in practicing the incredible feat of transporting a site into another one without deformation through massive transformations" (Latour, 2005, page 223).

Such immutability is not a given; it takes effort (Latour 1993). To remain immutable as it travels between and stabilises different sites of humanitarian shelter crises, the emergency family tent must first be manufactured by the various contractors used by UNHCR, IFRC and ICRC, at various locations around the world, with the same material form as intended by its designers. In order to ensure that all contractors and subcontractors producing the emergency family tent are actually producing more or less identical material products, the specifications for the tent use exacting language and widely standardised measurements. Detailed in a 22 page document, these specifications contain precise information on manufacturing materials, metric measurements, required minimum testing values (for example for the tensile strength of the canvas) and even on which standard typeface is to be used for agency logos (for UNHCR, for example, the logo must use Helvetica Bold typeface, printed in Pantone Blue 300 or quadrichrome CMYK $(\mathrm{C}=100 \%, \mathrm{M}=45 \%, \mathrm{Y}=0 \%, \mathrm{~K}=0 \%$ ) (UNHCR, 2010)). This precise language, drawing on widely available standards, allows a highly mobile written document - the emergency family tent specifications - to be translated into more or less materially identical tents at different factories in different places around the world. As the IFRC procurement website reads on a page describing the new emergency family tent, "[t]he generic design specifications ensure that the product can be manufactured in numerous countries by suppliers with standard technical know-how and standard tent-industry equipment” (IFRC, 2011). 
Secondly, in order for the family tent to remain the same wherever it is implemented, it must also be assembled in different places of humanitarian crises as its designers intended. To this end, a six page illustrated instruction sheet for step-by-step tent assembly is distributed alongside the flat-packed tents. These instructions include 26 steps with corresponding illustrations for correctly assembling the tent, as well as precise instructions for how a group of tents (as for a camp) must be laid out. The latter sets out the exact standards and measurements to be used for firebreaks, minimum distance between tents, minimum amounts of open and covered space required per person, and the distance to be observed between tents and water points, latrines, washing facilities and refuse bins (IFRC, 2010). The instructions also include other tips and directions for assembly under various potential contingencies, for example giving installation tips for assembling tents in high winds or torrential rain, advice for ensuring fire safety within and between tents, and instructions on how to extend the life of the tent, which is expected to last a minimum of one year once in use if assembled and used as directed.

The level of detail in the tent assembly instructions allows the context in which the emergency family tent works as an emergency shelter response to travel alongside the tent itself. Like Redfield's biomedical kits, as it moves into the sites of humanitarian crises the emergency family tent partly reconfigures particular, local spaces around its own globally standardised materiality and the uniform spatial configuration dictated by its instructions. As such, the emergency family tent enacts humanitarian spaces associated with the response to flooding in one place in more or less the same way as it does with the response to an earthquake in another and to violent conflict in yet another. In short, the immutable mobility of the emergency family tent enacts humanitarian spaces within a network topology, characterised by the stabilisation of associations (Law and Mol 2001). 
Because it does not change in accordance with the unique qualities of each crisis, but instead partly re-orders these qualities according to its own standard, inflexible material form and script, the network topology of the emergency family tent informs a homogenised topography of humanitarian space. Indeed, the visual repetition of identical white tents uniformly assembled across different landscapes of disaster is an instantly recognisable image of humanitarian disaster and assistance, inviting charges along the lines of Debrix's accusation that transnational humanitarian action dissolves the specificities between different located humanitarian crises into "a succession of similar, interchangeable catastrophic visual sites" (1998, page 843). This homogenisation of places in the name of emergency has been implicated in the reduction of the lives saved by humanitarian action to what Agamben (1998), expanding on Arendt (1958), refers to as 'bare life' - mere biological existence. By holding the specificities of each particular humanitarian crisis outside of the humanitarian spaces it effects, the emergency family tent acts to exclude considerations of the different, complex psycho-social lives of those it saves. To more fully understand this reducing of the lives saved in humanitarian space to bare lives stripped of individual complexities, it is critical to also consider the temporal orientation of humanitarian spaces enacted within a network topology.

\section{Network topology and the emergency temporality}

As a number of observers have argued, the conventional framing of humanitarian crises is one of emergency (e.g. Calhoun 2004; 2008; Fassin and Pandolfi 2010; Pandolfi 2003; 2008). Emergency, as Calhoun explains (2004, page 375), implies a sudden exception to, or rupture of, the 'normal' functioning of society and carries the corollary that urgent action is required to save lives and restore order. Within this emergency imaginary, humanitarian space is shaped as what Redfield calls a "historical deferment" 
(2005, page 346), where both the past and future are ignored in favour of addressing a radical present of immediate human suffering and "action (especially technical, expert action) acquires self-authorising status by virtue of circumstance” (Redfield 2005, page 337). In this foreshortened temporal horizon of emergency, difference is held outside of the relations of humanitarian space in the name of urgency with the result that the possibility of elaborated human existence -including the possibility of human dignity - is also held outside of this space, deferred until the end of crisis (Agamben 1998; Fassin 2012; Redfield, 2005).

The emergency family tent embodies this conventional framing of humanitarian crisis as emergency in its material form and mobility. Designed to stabilise action in the urgent present of a crisis, emergency family tents are flat packed for shipping, selfcontained - each individual package requires no additional materials to function as a shelter - and take no more than a few hours to assemble. As such, large numbers of emergency family tents can be moved rapidly to the sites of humanitarian crises to be distributed directly to affected households or to be set up by aid agencies to form the tent cities that often serve as refugee or internally displaced person (IDP) camps. Indeed, in its ability to rapidly save (bare) lives and alleviate suffering, the mobility and materiality of the emergency family tent orders humanitarian space according to the emergency imaginary and associated emergency temporality of humanitarian action.

Given this intense focus on saving lives and alleviating suffering in the foreshortened temporal horizon of emergency, it should come as no surprise that the lifespan of the emergency family tent itself is also limited: their life expectancy is estimated to be one year, after which time they are expected to be uninhabitable and to have little to no market value. This limited lifespan means that those provided with 
emergency family tents to relieve their homelessness in the immediate aftermath of crisis may be left homeless again in one year's time when the tent's deterioration leaves it unable to give shelter. However, for humanitarian action aimed at saving lives in the urgent present of an emergency, the potential future lack of shelter that maybe caused when an emergency family tent ceases to work as a shelter is outside of the specific concerns of humanitarian action. As the emergency temporality commands a space of action separated from past contexts and future potentialities, the emergency family tent's only role is to stabilise rupture in the urgent present of crisis. In one year's time, the humanitarian ('emergency') phase is expected to have passed, leaving the 'normal' problem of providing shelter to populations in need to governments and/or development actors like the UNDP.

In this way, the network topology associated with the emergency family tent underlies a topographical rendering of humanitarian space not only as partially homogenised space, but as a space temporally limited to the initial phase in a sequential timeline of action after crisis. In the temporal imagination of crisis as rupture, humanitarian space is drawn as the immediate space of stabilisation. Once the contours of emergency space have been stabilised, a topography of 'normal' space - drawn by lines of state or development action - is restored. Sometimes an 'early recovery' phase is inserted into this temporal imagination between the phases of rupture and normalcy, but the movement remains the same: a linear, sequential progression from one phase to the next. Within this sequential ordering of space, shelter is understood as an object, or series of objects, deployed according to the phase in the sequence, such that the sequence of temporal phases, humanitarian $\rightarrow$ recovery $\rightarrow$ development, corresponds to the sequence of shelter objects, tent $\rightarrow$ temporary shelter $\rightarrow$ permanent shelter. In this rendering, the 
emergency family tent needs only to last as long as the humanitarian space phase in the sequence. Since the latter is temporally limited to the immediate aftermath of crisis, the limited lifespan of the tent does not appear as a problem in this sequential topography.

Though they convey a conventional framing of humanitarian crisis as emergency, the material and mobile humanitarian practices associated with the emergency family tent are not without critics. After all, the lived experience of humanitarian crises is heterogeneous, messy, sometimes protracted and therefore often resistant to the neatly delimited temporal imaginary of emergency. Reflecting on the sometimes long gap between crisis and recovery, a UNDP official told me,

You know, that you save lives is fine today, what about tomorrow? ... when you leave you're going to create another crisis and that's going to be a silent crisis because CNN will not be there, you know, it disappeared from the screens and the humanitarians are not there to respond and the development actors are not there yet.

Concerns over the appropriateness of homogenous tents for relieving heterogeneous shelter crises are reflected in the development and use of another shelter device, the IFRC shelter kit. In what follows, I turn to tracing the humanitarian space effected through the mobile and material practices and temporal orientation associated with this shelter kit.

\section{Humanitarian space as fluid topology}

Put forward with the slogan 'build back better', the IFRC promotes the shelter kit as a more flexible, cost effective, and inclusive alternative to tents for solving emergency shelter problems. The IFRC shelter kit is a standardised collection of tools, fixings (i.e. rope, nails), and two tarpaulins. Like tents, the distribution of tools, tarpaulins and building materials has a long history in humanitarian shelter responses and, like the 
emergency family tent, the contents of IFRC shelter kits are manufactured to exact specifications. Despite such similarities, however, the IFRC shelter kit exhibits a number of critical differences from the emergency family tent.

First, whereas the emergency family tent is designed to be a self-contained emergency shelter, requiring no additional materials to function as intended, the shelter kit is specifically intended to be used in combination with locally salvaged or procured building materials (e.g. bamboo, corrugated metal, concrete, etc.) for either building emergency shelters or for repairing existing buildings that have been damaged. Second, whereas the emergency family tent does not change its material form over time - other than through deterioration - the designers of the shelter kit intend shelters built or repaired using the shelter kit to be added to and adapted over time such that they might be transformed into transitional shelters and even, eventually, into permanent homes. Third, rather than being solely intended for shelter, the items provided in the shelter kit can be used for auxiliary shelter tasks such as clearing rubble and digging drainage ditches, for building or repairing essential non-shelter structures such as latrines and water collection points, and for tasks associated with livelihoods such as repairing damaged fishing boats or agricultural buildings.

Finally, whereas the emergency family tent is standardised to be more or less identical in material form, the shelter kit is standardised to be changeable. That is, although each component of the shelter kit is made to exact, standardised specifications, and there is a standard collection of items that constitute the shelter kit, some items may be left out and/or others added to the kit as deemed appropriate to meet the specific needs of each particular crisis. Rather than precise instructions for assembly and configuration, the 'script' with which the shelter kit travels is an 88 page guidance booklet. Instead of giving 
exact instructions for how to use the shelter kits, this guidance booklet advises humanitarian organisations on how to adapt the contents of the kit or how items in the kit may be used in different ways to fit the particular circumstances of different crises. For example, in situations where violent conflict is ongoing, the booklet advises excluding machetes from the kits' contents; in situations where building materials will be difficult to salvage or procure locally, it advises including construction materials on top of the kit's standard contents, and so on. To streamline the process of kit modification and minimise delays in procurement, the IFRC has precise specifications on hand for most of the items suggested as possible additions or substitutions to the shelter kit.

Exemplifying the process of kit adaptation, in the areas of Myanmar affected by Cyclone Nargis in 2008, the shelter kit was adapted for use in building with bamboo, the building material most typically used in local construction techniques there and which could be procured locally without causing significant environmental damage (as might be the case, for example, with hardwood construction). Many items in the shelter kit distributed to victims of Cyclone Nargis matched those from the standard shelter kit, including a machete, handsaw, claw hammer, nails and rope. Items for working with metal, however, such as tin snips and roofing nails, were left out and some items particularly useful for building with bamboo, including a chisel set for joinery and a sharpener for the machete, were added. The modification of the contents of the shelter kit distributed in Myanmar was not only possible, but is now put forward by the IFRC as a positive example of how deploying flexible shelter kits instead of tents can optimise shelter responses in different settings. ${ }^{7}$

\footnotetext{
${ }^{7}$ For example, an entire session of a Shelter Cluster training event I attended in 2010 was devoted to the Myanmar example as a positive example of what the shelter kit "can do".
} 
Given these characteristics, the shelter kit can hardly be described as an immutable mobile like the emergency family tent. Rather, the shelter kit is better described as a mutable mobile, exhibiting configurational variance as it moves between sites (Law and Mol, 2001). As Redfield's example of MSF's biomedical kit was useful for discussing the immutable mobility of the emergency family tent above, here it is useful to take a moment to consider the Zimbabwe Bush Pump described by Marianne de Laet and Annemarie Mol (2000), a quintessential example of mutable mobility. De Laet and Mol note three notable characteristics of the Zimbabwe Bush Pump: first, the material composition of the Bush Pump is slightly different from one place and time to another parts sometimes fall off or break down and are replaced with different ones or new components are added that are not part of its original design. Second, as it moves between different sites, the Bush Pump takes on various meanings and uses: it is, of course, a mechanical device for supplying water, but in some sites it has also been a tool for promoting health and in others a tool for building community. Third, with its multiple uses and materialities, the Bush Pump extends the possibilities of what is means for it to work beyond a binary yes or no, such that "there are many grades and shades of 'working'; there are adaptations and variants" (de Laet and Mol, 2000, page 225). Despite its characteristic variances, however, it makes sense to say the Zimbabwe Bush Pump is the same pump from one site to the next because these variances are an intentional - and integral - part of its design (Law and Mol, 2001).

As with the Bush Pump, the material composition of the shelter kit is designed to be changeable. As noted above, the contents of the shelter kit will be similar but not necessarily exactly the same in each shelter response where it is deployed. Indeed, the contents of the shelter kit need not be invariable for it to remain recognisable as an IFRC 
shelter kit. Of course, if all the components of the kit were switched at once, it would indeed cease to be the same kit. The key to remaining the same in the case of the shelter kit is that, although its contents may change from crisis to crisis, this change is always just partial and always involves some combination of tarpaulins, rope and various building tools built to IFRC specifications.

Also like the Bush Pump, the shelter kit holds different purposes and meanings. It is a collection of material objects for constructing and/or repairing shelters in the immediate aftermath of a humanitarian crisis. For the IFRC and its partners, however, the shelter kit is also intended to recognise local capacities and involve affected households in their own humanitarian relief and recovery processes. Highlighting this potential meaning, the introduction of the shelter kit guidance booklet reads:

Rather than waiting for the provision of tents or other such temporary shelter solutions, many people whose homes are affected by natural disasters begin the sheltering process themselves, using materials they are able to salvage from their damaged homes or sourced from their surroundings and with whatever tools they are able to access. Relief items, such as plastic sheeting or tarpaulins, as well as basic tools, rope, and fixings such as nails, valuably aid such households to rapidly provide their own shelter solutions or to make damaged houses habitable. (IFRC, 2009, page i)

Attaching the shelter kit's meaning to a currently fashionable approach of 'helping people help themselves' in the provision of humanitarian aid, the guidance booklet goes on to underline the kits role in supporting "people helping themselves to provide appropriate shelter" (IFRC, 2009, page i). By putting forward this potential meaning, the shelter kit aims to, at least partly, blur the boundaries between the givers and receivers of aid and between humanitarian relief, recovery and development. So, in addition to being a collection of material objects for effecting emergency shelters, the shelter kit can also 
function as a means of recognising local differences and involving people in their own relief and recovery process.

Finally, whether or not the shelter kit 'works' as a shelter response cannot be easily answered with a yes or no. Where the emergency family tent presents a more or less binary emergency shelter solution as far as transnational humanitarian actors are concerned - if it is made to specification and set up properly it is working, if it is not made to specification or is set up incorrectly it is not working - what constitutes 'working' in the case of the shelter kit varies depending on the particular context in which it is used and on which meaning one is asking about. Deploying the shelter kit necessarily results in different material forms of emergency shelter of widely varying quality depending on the available building materials, local building styles and capacities, and a host of other factors related to the particularity of each crisis. Within a single affected community the shelter kit might work to provide emergency shelters for some households, for example for those with skilled and able-bodied members, but not for others who lack the capacity to engage in building and repairing activities. In addition, in cases where humanitarian organisations take on extensive roles in helping in the design and construction of emergency shelters using the shelter kit, it could work in the provision of emergency shelter but fail to work as a tool for involving communities in their own relief and recovery. The question of whether or not the shelter kit is working, then, cannot be answered with a simple yes or no.

Thus, although both the emergency family tent and the shelter kit may be said to connect sites across space and over time by staying the same as they move, what it means for each to be 'the same' is different. For the emergency family tent, staying the same is a matter of maintaining a more or less identical material form and more or less the same 
spatial relationships of emergency shelter as it moves and connects sites across space and over time. For the shelter kit, conversely, staying the same is a matter of having a similar but malleable material form that adapts to local contexts and effects different spatial relationships of emergency shelter in different sites.

It is not despite but because of its changeability that the shelter kit connects sites of humanitarian crisis across space and over time as it moves. A fluid topology allows connections to be less solid, opening relationships to subtle changes and variance from one place and time to another (Law and Mol, 2001; see also Callon and Law, 2004). Moreover, such fluidity, Law and Mol (2001, page 614) suggest, may be necessary to maintain relational connections in "a world in which invariance is likely to lead to rupture, difference, and distance. In which the attempt to hold relations constant is likely to erode continuity". The shelter kit, in effecting shelter that changes its material form over time, seeks to avoid the future of secondary rupture potentially caused by the tent when it ceases to work after one year. In this process, moreover, the shelter kit selfconsciously aims to enact - together with its recipients - globally heterogeneous humanitarian spaces. However, though it opens the possibility of including difference within, rather than holding it outside of, humanitarian space, this vision of inclusiveness, as the following section explores, also has its limits and homogenising tendencies.

\section{Fluid topology and the temporality of transformation}

Like the family tent, the standardisation embodied in the shelter kit is envisioned as increasing the speed at which shelter responses can be effected, thereby saving lives in the urgent present of a crisis. Underlining this point, the IFRC guidance booklet on the shelter kit reads: 
Although distribution of construction materials and tools has been a component of shelter relief programmes in many emergencies, until recently such assistance packages have only been developed after the disasters, a process that takes time and leads to inconsistencies in specifications and quality. By creating a standardised shelter kit, pre-positioned regionally in significant quantities using defined and tested specifications, IFRC has significantly improved the speed of delivery and predictability at the start of shelter responses. (IFRC 2009, page i)

At the same time as it is intended to save lives and alleviate suffering in the urgent present of crisis, however, the shelter kit is also designed with a view toward sustaining the lives it saves. As detailed above, the kit is widely adaptable and capable of producing emergency shelters that are expected evolve over time into temporary and then permanent structures, thus providing life saving shelter in the present while minimising the potential of a second shelter disruption in the future. In other words, the temporality of the shelter kit is not limited to the immediate present of emergency, but extends into the past by drawing on the particular learned skills and socio-historical contexts of particular communities that inform how the shelter kit will be used and what sort of shelters are produced with it, as well as into the future in its promise of retaining value and supporting livelihoods after the moment of emergency has passed.

Underlining its temporal imagination of humanitarian space responsive to the past and open to the future, the proponents of the shelter kit are working to de-emphasise understandings of shelter as a specific object corresponding to a definite phase of crisis response and reframe it instead as a process. Instead of talking about types of shelter (such as emergency, temporary, permanent), this reframing emphasises talking about sheltering, in which effecting emergency shelter, as an IFRC meta-evaluation reminds, is "only the start of an evolving process" (Davidson and Price, 2011, page 8). The fluid 
topology of the shelter kit, then, is entwined with a temporal imaginary of transformation.

Unlike the sequential timeline of rupture, stabilisation and normalcy enacted in the topographical renderings of humanitarian space by the emergency imaginary of the emergency family tent, the shelter kit's temporal imaginary of transformation renders a timeline of humanitarian space characterised by overlapping and even simultaneous concerns all of which may be adapted as they unfold (Law and Mol, 2010). Recovery and development action are not excluded from humanitarian space in this timeline, deferred until the situation is stabilised, but rather invited to coincide with humanitarian space as part of a multivalent process of sheltering within a normative framing of positive transformation ('building back better’).

At the same time, the expanded temporal horizon of humanitarian space enacted with the shelter kit remains partial. It is not the fully expanded, transformational temporality embraced (if not necessarily realised) by human rights or development actors. The exact contents of kits, though adapted to meet specific community needs, are chosen by humanitarian shelter experts based on past organisational experiences and expert knowledge, prior to any input from the communities to which they are distributed and thus maintaining a degree of homogeneity. Moreover, the IFRC, as with most other specifically humanitarian actors, does not remain in the sites of crisis long enough to see if the inclusive and sustaining imaginary of humanitarian space forwarded by the shelter kit's design is ever realised. ${ }^{8}$ Its Memo of Understanding with OCHA, IFRC is careful to

\footnotetext{
${ }^{8}$ Although evaluations of the 'effectiveness' of humanitarian responses have become commonplace (Fredriksen 2012), the lack of sustained engagement with the places of humanitarian crises is a persistent obstacle to effective assessment of such longer term outcomes. Indeed, an extended place-based analysis of how affected populations in specific crises interact with devices like tents and kits, though beyond the scope of the current article, presents an important topic for further social scientific research.
} 
delimit its leadership of the shelter cluster to the emergency phase, expected to last the first three months after the onset of a crisis, thus maintaining an attachment to a topographical rendering of humanitarian space as first in a temporally delineated sequence. Accordingly, although the materiality of the shelter kit attempts to account for past associations and remain open to possible future associations beyond the moment of crisis, as with the CARE packages described by Ilana Feldman (2011), its success is measured at the point of delivery. The potential to sustain complex psycho-social lives remains just that, a potential, not fully accounted for in the material and mobile practices and temporality of the shelter kit.

\section{Conclusion}

The deployment of the emergency family tent versus the shelter kit is not simply a matter of populating a pregiven humanitarian space (as a Cartesian container) with one or another material form of emergency shelter. Rather, the material form and mobilities of each of these devices effects different topological associations of humanitarian space, which in turn inform different topographical renderings of that space. To review, the material form and mobility of the emergency family tent corresponds to a network topology. Acting as an 'immutable mobile', the tent moves between and connects different sites of humanitarian crises with each other by stabilising spatial and temporal relationships of humanitarian response. The material form and mobility of the shelter kit, by contrast, correspond to a fluid topology. Acting as a 'mutable mobile', the kit moves between and connects different sites of humanitarian crisis not by stabilising relationships, but instead by adapting to a wide variety of local contexts, meanings and conditions. 
These two different 'shelter topologies', moreover, underlie different topographic renderings of the lines and contours of humanitarian space. The network topology associated with the emergency family tent renders humanitarian spaces partially homogenous, reordering the material spaces of crisis around its own inflexible form and script. By contrast, the fluid topology of the shelter kit is such that it partially adapts to, rather than redrawing, the pre-existing topographies of different sites of crisis. Each of these spaces, in turn, conveys different assumptions about crisis response. For example in the first, difference is held outside of this humanitarian space in the name of increasing the speed and efficiency of saving lives in the urgent present of emergency. In the second, difference is enlisted as a potential ally in a potentially transformative humanitarian space in which affected communities 'build back better'. The first traces humanitarian space as a space of exception, set apart and temporally circumscribed to the immediate aftermath of crisis. The latter traces humanitarian spaces as open and overlapping with multiple forms of action, temporally indefinite in its reference to both past context and future potentials. The first conveys an imaginary of humanitarian space as limited to a space for saving bare lives in the moment of emergency, deferring considerations of complex psycho-social life for the spaces of recovery or development to follow. The second conveys an imaginary of a space capable of saving bare lives and sustaining the complex psycho-social lives of individuals and communities that participate in their own relief, recovery and development. Thus, instead of standing in opposition to, or disconnect with, abstract formulations of humanitarian space, each of these technical devices for responding to humanitarian shelter crises has been shown to convey in its material design and mobility certain sets of assumptions and concerns derived from such competing formulations. 
Of course, these topographical tracings of the humanitarian space of emergency family tents and that of shelter kits remain ideal-typical, tended towards but never fully realised in practice. On the one hand, the emergency family tent can never entirely exclude difference - the particular, situated elements of each site of humanitarian crisis will always interact with, collaborate with and resist its standardising tendencies in the enacting of transnational spaces (see Massey, 2005). Thus the homogenisation of space it effects will always be partial and provisional and complex, heterogeneous psycho-social elements of the bare lives it saves will sometimes surface. On the other hand, the shelter kit, though flexible, is dependent on the decisions and knowledges of global experts prior to and outside of the involvement of affected communities. The future possibilities the shelter kit is intended to open up may never be realised and, indeed, are notably much less likely to be realised for those displaced by violence than for those displaced by natural disaster. In cases of extended or cyclical crisis, meanwhile, it may prove to be a future indefinitely deferred. Intended as an alternative to the emergency family tent's inflexibility, the shelter kit retains some homogenising tendencies and attachments to sequential time in which humanitarian action is temporally circumscribed and thus never fully inclusive of difference or capable of sustaining psycho-socially complex lives.

On a final note, the intent in tracing these topological associations of humanitarian space as effected through different shelter devises has not been to reify any particular topographical renderings of that space. Rather, it has been to illustrate how different humanitarian spaces - conveying different humanitarian intentions, imaginaries and biopolitical effects - come to be enacted in the mobile and material practices and temporalities of humanitarian response. By attending to the topological associations of 
humanitarian practice as this article has done, we can trace more meaningful, lively

topographies of humanitarian space.

\section{References}

Agamben G, 1998 Homo Sacer: Sovereign Power and Bare Life (Stanford University Press, Stanford)

Akrich, M 1992, "The de-scription of technological objects", in Shaping Technology/Building Society: Studies in Sociotechnical Change Eds W E Bijker, J Law (MIT Press, Cambridge, MA) pp 205-224

Arendt H, 1958 The Human Condition (University of Chicago Press, Chicago)

Barnett M, 2008, "Humanitarianism as a Scholarly Vocation", in Humanitarianism in Question: Politics, Power, Ethics Eds M Barnett, T G Weiss (Cornell University Press, Ithaca, NY) pp 235-263

Berthaut G, 1912, "Topographie, topométrie et topologie: Lettre du Général Berthaut a Mr Paul Girardin" Annales de Géographie 21 73-80

Calhoun C, 2004, "A World of Emergencies: Fear, Intervention, and the Limits of Cosmopolitan Order" Canadian Review of Sociology and Anthropology 41 373-395

Calhoun C, 2008, "The imperative to reduce suffering: Charity, progress, and emergencies in the field of humanitarian action", in Humanitarianism in Question: Politics, Power, Ethics Eds M Barnett, T G Weiss (Cornell University Press, Ithaca) pp 73-97

Callon M, Law J, 2004, "Introduction: absence-presence, circulation, and encountering in complex space, Guest Editorial" Environment and Planning D: Society and Space 22 311

Collinson S, Elhawary S, 2012, "Humanitarian space: a review of trends and issues", in $H P G$ Report 32 (Overseas Development Institute, London)

Cowen D, 2010, "A geography of logistics: market authority and the security of supply chains" Annals of the Association of American Geographers 100 600-620

Davidson S, Price G, 2011 Review of the international Federation's Shelter Cluster commitment. (IFRC, Geneva)

Debrix F, 1998, "Deterritorialised territories, borderless borders: the new geography of international medical assistance" Third World Quarterly 19 827-846

de Laet M, Mol A, 2000, "The Zimbabwe bush pump: mechanisms of a fluid technology" Social studies of science 30 225-263

Deleuze G, 1988 Bergsonism (Zone Books, New York)

Eisenstein E, 1979, The Printing Press as an Agent of Change (Cambridge University Press, Cambridge)

Fassin D, 2012 Humanitarian Reason: A Moral History of the Present (University of California Press, Berkeley)

Fassin D, Pandolfi M, 2010, "Introduction: Military and Humanitarian Government in the Age of Intervention", in Contemporary States of Emergency: The Politics of Military and Humanitarian Interventions Eds D Fassin, M Pandolfi (Zone Books, New York) pp 9-25

Feldman I, 2011, "The Humanitarian Circuit: Relief Work, Development Assistance, and CARE in Gaza, 1955-67", in Forces of Compassion: Humanitarianism Between Ethics and Politics Eds E Bornstein, P Redfield (School for Advanced Research, Santa Fe) pp 203-226 
Fredriksen A, 2012, Making Humanitarian Spaces Global: Coordinating Crisis Response through the Cluster Approach, Unpublished PhD Dissertation, Sociology, Columbia University

Haraway D, 1991 Simians, Cyborgs and Women: The Reinvention of Nature (Routledge, London)

Hubert D, Brassard-Boudreau C, 2010, "Shrinking Humanitarian Space? Trends and Prospects on Security and Access" The Journal of Humanitarian Assistance http://sites.tufts.edu/jha/archives/863

Ignatieff M, 1997 The Warrior's Honor: Ethnic War and Modern Conscience (Henry Holt \& Company, New York)

IFRC, 2009 The IFRC Shelter Kit (IFRC, Geneva)

IFRC, 2010, "Family tent 16m2 instruction sheet", (IFRC, Geneva )

IFRC, 2011, "New Family Tent specification", (IFRC, Geneva) http://procurement.ifrc.org/en/news/Pages/20090701_NewFamilyTent.aspx

Knorr-Cetina K, 1997, "Sociality with objects: Social relations in postsocial knowledge societies" Theory, Culture and Society 14 1-30

Lacy M, 2008, "Designer Security: Control Society and MoMA's SAFE: design takes on risk" Security Dialogue 39 333-357

Latham R, Sassen S, 2005 Digital Formations: IT and New Architectures in teh Global Realm (Princeton University Press, Princeton)

Latour B, 1986, "Visualization and Cognition: Thinking with eyes and hands" Knowledge and society $61-40$

Latour B, 1991, "Technology is society made durable", in A Sociology of Monsters Ed J Law (Routledge, London)

Latour B, 1992, "Where are the missing masses? The sociology of a few mundane artifacts", in Shaping Technology/Building Society: Studies in Sociotechnical Change Eds W E Bijker, J Law (MIT Press, Cambridge, MA) pp 225-258

Latour B, 1993 The Pasteurization of France (Harvard University Press, Cambridge, MA)

Latour B, 2005 Reassembling the Social: An Introduction to Actor-Network Theory (Oxford University Press, Oxford)

Law J, Hassard J, 1999 Actor network theory and after (Wiley-Blackwell, Malden, MA)

Law J, Mol A, 2001, "Situating technoscience: an inquiry into spatialities" Environment and planning D, society and space $19609-621$

Law J, Mol A, 2010, "Veterinary Realities: What is Foot and Mouth Disease?" Sociologia Ruralis $\mathbf{5 1} 1-16$

Marres N, 2012 Material Participation: Technology, the Environment and Everyday Publics (Palgrave Macmillan, New York)

Massey D, 2005 For Space (Sage, London)

Matthes F E, 1912, "Topology, Topography, Topometry" Bulletin of the American Geographic Society 44 334-339

Mol A, Law J, 1994, "Regions, networks and fluids: Anaemia and social topology" Social studies of science 24 641-671

Mol A, 2002 The Body Multiple: Ontology in Medical Practice (Duke University Press, Durham, NC)

Pandolfi M, 2003, "Contract of Mutual Indifference: Governance and the Humanitarian Apparatus in Contemporary Albania and Kosovo" Indiana Journal of Global Legal Studies 10 369-38

Pandolfi M, 2008, "Laboratory of Intervention: The Humanitarian Governance of the Postcommunist Balkan Territories", in Postcolonial Disorders Eds M D Good, S Hyde, S Pinto, B Good (University of California Press, Berkley) 
Redfield P, 2005, "Doctors, borders, and life in crisis" Cultural Anthropology 20 328-361

Redfield P, 2008, "Vital Mobility and the Humanitarian Kit", in Biosecurity Interventions: Global Health and Security in Question Eds A Lakoff, S J Collier (Columbia University Press, New York) pp 147-172

Redfield P, 2011, "The Impossible Problem of Neutrality", in Forces of Compassion: Humanitarianism Between Ethics and Politics Eds E Bornstein, P Redfield (School for Advanced Research, Santa Fe) pp 53-70

Redfield P, 2013 Life in Crisis: The Ethical Journey of Doctors Without Borders (University of California Press, Berkeley)

Rieff D, 2002 A Bed for the Night: Humanitarianism in Crisis (Simon \& Schuster, New York)

Rose M, Wylie J, 2006, "Animating landscape" Environment and Planning D: Society and Space 24 475-479

Taylor P J, 1994, "The State as Container: Territoriality in the Modern World-System" Progress in Human Geography 18 151-162

Tennant V, Doyle B, Mazou R, 2010 Safeguarding Humanitarian Space: a Review of Key Challenges for UNHCR (UNHCR, Geneva)

Terry F, 2002 Condemned to repeat?: The paradox of humanitarian action (Cornell University Press, Ithaca, NY)

Thrift N, 2006, "Space" Theory, Culture and Society 23 139-155

Tsui E, Myint-U T, 2004, "The institutional response: creating a framework in response to new challenges", in The Humanitarian Decade: Challenges for Humanitarian Assistance in the last decade and into the future, Vol. II: The development of practice, principles and the humanitarian framework (OCHA, New York) pp 1-14

Weizman E, 2007 Hollow Land: Israel's Architecture of Occupation (Verso, London) 